\title{
Effects of Increased Heart Rate and Sympathetic Tone on Intraventricular Electrogram Morphology
}

\author{
Cynthia J. Finelli, MSE, Lorenzo A. DiCarlo, MD, Janice M. Jenkins, PhD, \\ Stuart A. Winston, DO, and Pai-Chi Li, MSE
}

Electrogram pattern recognition by way of morphologic analysis has been proposed as a technique that may improve discrimination of ventricular tachycardia from sinus rhythm by antitachycardia devices. The potential impact that increases in heart rate and sympathetic tone could have on such techniques, however, has not been previously determined. A comparative study was undertaken to quantify possible changes in ventricular electrogram morphology using correlation waveform, area of difference, and amplitude analyses in 6 patients during atrial overdrive pacing at cycle lengths of 600 and $400 \mathrm{~ms}$ (group A), in 13 patients during infusions of physiologic doses of epinephrine (group $B)$, and in 20 patients undergoing infusions of isoproterenol (group C). Four patients were in both groups $\mathbf{A}$ and $\mathbf{B}$. A bipolar intraventricular template of cardiac depolarization during sinus rhythm at rest was compared with depolarization during subsequent passages of sinus rhythm at rest and subsequently increased heart rate.

In 36 of 39 patients, waveform configuration as assessed by correlation waveform analysis remained relatively stable during atrial overdrive pacing, epinephrine infusion, and isoproterenol infusion when compared with sinus rhythm at rest. The correlation value did not fall below 0.950 in any patient. Area of difference values for the same 36 patients changed by an average of 6 and $37 \%$ during atrial overdrive pacing at cycle lengths of 600 and $\mathbf{4 0 0}$ ms intervals, respectively, by $3 \%$ during epinephrine infusion,

From the Department of Electrical Engineering and Computer Science and School of Medicine at the University of Michigan, Ann Arbor, and the Cardiac Electrophysiology Laboratory at St. Joseph Mercy Hospital of the Catherine McAuley Health Center, Ann Arbor, Michigan. This study was supported in part by Grant BCS-8909042 from the National Science Foundation, Washington D.C., and by Cardiac Pacemakers, Inc. Ms. Finelli is a CPI Research Fellow. Manuscript received April 22, 1991; revised manuscript received and accepted July 12, 1991.

Address for reprints: Cynthia J. Finelli, MSE, Department of Elcctrical Engineering and Computer Science, 4421 EECS Building - Medical Computing Laboratory, 1301 Beal Avenue, Ann Arbor, Michigan 48109-2122. and by $17 \%$ during isoproterenol infusion. In these same patients, there was an average change in electrogram amplitude of $-1 \%$ during atrial overdrive pacing at $600 \mathrm{~ms}, 26 \%$ during pacing at $400 \mathrm{~ms},-1 \%$ during epinephrine infusion, and $12 \%$ during isoproterenol infusion.

Little or no correlation was found between relative changes of amplitude and changes of correlation coefficient during any intervention. However, changes in amplitude and changes in area of difference exhibited weak to moderate correlation during infusion of epinephrine and isoproterenol. Despite some amplitude variation, overall waveform morphology remains relatively constant during Increases in heart rate with or without concurrent changes in sympathetic tone. These findings suggest that heart rate increases are unlikely to confound time-domain detection schemes used in antitachycardia devices.

(Am J Cardiol 1991;68:1321-1328)

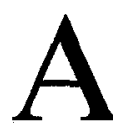
variety of methods for analyzing intracardiac electrograms have been proposed for arrhythmia detection by antitachycardia devices. Such methods include rate onset and stability, ${ }^{l}$ multichannel timing analysis, ${ }^{2-4}$ gradient pattern detection, ${ }^{5,6}$ analysis of arrhythmia frequency spectra ${ }^{7-9}$ area of difference, ${ }^{10,11}$ and correlation waveform analysis. ${ }^{12-17}$ However, with the exception of preliminary investigations by Paul $^{18}$ and Rosenheck ${ }^{19}$ and their co-workers in humans, and Tomaselli et $\mathrm{al}^{20}$ in dogs, most studies to date have been performed on electrocardiographic signals recorded from patients in a resting state. Whether the results of waveform analysis techniques designed to recognize abnormal ventricular activation might be affected hy increases in heart rate alone or by accelerations in heart rate due to changes in sympathetic tone has not been determined with certainty. This study examined the effects on intraventricular electrogram morphology caused by (1) increases in heart rate alone during atrial overdrive pacing, and (2) changes in heart rate and sympathetic tone due to intravenous infusions of either a $\beta$ or a combined $\alpha$ and $\beta$ agonist. 


\section{METHODS}

Patient group: Thirty-five patients were entered into this study after giving informed consent and were categorized into 3 groups. Group A included 6 patients ( 3 women aged $40 \pm 16$ years and $3 \mathrm{mcn}$ aged $49 \pm 18$ years) studied during atrial overdrive pacing rates of 100 beats $/ \mathrm{min}$ ( $600 \mathrm{~ms}$ intervals) and 150 beats $/ \mathrm{min}$ (400 ms intervals). Group B consisted of 13 patients ( 4 from group $A$ and 9 additional) (5 women aged $44 \pm$ 13 years and 8 men aged $50 \pm 14$ years) undergoing epinephrine infusion. Group $C$ was composed of 20 patients $(9$ women aged $58 \pm 16$ years and 11 men aged $51 \pm 16$ years) studied during infusion of isoproterenol. No patient was receiving antiarrhythmic drugs at the time of the electrophysiologic study. Nineteen patients had no prior evidence of heart disease, 13 had coronary artery disease, 1 had a previous myocardial infarction, 1 had mitral valve prolapse and 1 had myotonic dystrophy.

Electrophysiology study: Patient data were acquired from bipolar electrode catheters with $1 \mathrm{~cm}$ interelectrode spacing during elective cardiac electrophysiologic studies as described previously. ${ }^{14}$ In the resting state, a 12-lead electrocardiogram was recorded during sinus rhythm for baseline measurement purposes. The patient was then either stimulated with atrial overdrive pacing at a cycle length of $600 \mathrm{~ms}$ followed by pacing at intervals of $400 \mathrm{~ms}$ (group A), treated with a physiologic dose ${ }^{21}$ of an $\alpha$ and $\beta$ agonist, epinephrine (50 $\mathrm{ng} / \mathrm{kg} / \mathrm{min}$ ) (group B), or given a clinical infusion ${ }^{22}$ of a pure $\beta$ agonist, isoproterenol ( $2 \mu \mathrm{g} / \mathrm{min}$ ) (group C).

Electrocardiograms from 2 or 3 surface leads (from I, II, III and $V_{1}$ ), a high right atrial lead, and a right ventricular apical lead were amplified through either a Siemens Mingograf-7 (Siemens-Elema, Solna, Sweden) or a Honeywell Electronics-for-Medicine (Electronics-for-Medicine, Pleasantville, New York) data amplifier. Each channel was recorded with wide-band filter settings of 0.5 to $500 \mathrm{~Hz}$ (Siemens Mingograf-7) or 1 to $500 \mathrm{~Hz}$ (Honeywell Electronics-for-Medicine), and outputs were connected to a Hewlett-Packard 3968 A FM tape recorder (Hewlett-Packard, San Diego, California). Signals were recorded on magnetic tape at a speed of $3 \frac{3 / 4}{4}$ inches/s with an effective bandwidth of 0 to $1,250 \mathrm{~Hz}$. All recordings were obtained while patients were lying supine.

Intraventricular electrogram analysis: Intraventric ular electrograms were digitized at a sampling rate of $1,000 \mathrm{~Hz}$ using a personal computer. Two separate passages of sinus rhythm before clinical intervention were digitized; the first was used for template generation and the second for baseline analysis. Additional data were digitized from each pacing passage for group A patients, from a passage during epinephrine infusion for group B patients, and from a passage during isoprotere nol infusion for group $\mathrm{C}$ patients. The length of each digitized passage varied from 10 to 30 seconds,

The average cycle length of the control sinus rhythm passage and the passage during clinically acceleratcd heart rate was determined for each patient. The average decrease in absolute cycle length for each group was evaluated by a 2-tailed, paired Student's $t$ test, and a $\mathrm{p}$ value was derived to represent the overall significance of the decrease.

To perform electrogram analysis and quantitate the similarity or dissimilarity between ventricular depolarizations, an appropriate window of electrogram depolarization for analysis was chosen for each patient. The window was selected from a typical depolarization of the first sinus rhythm passage and, in order to exclude acute injury current during repolarization, included ventricular depolarization only by beginning at the first deviation from baseline and ending at the first evidence of repolarization. The initial window size was imposed on all subsequent analysis for the same patient.

A representative, signal-averaged template of the patient's normal sinus rhythm was compared individually with each ventricular depolarization of the second baseline passage of sinus rhythm using correlation waveform, area of difference, and amplitude analyses. Accurate alignment of the ventricular depolarization under analysis was effected by a sliding window meth$\mathrm{od}^{14}$ to compensate for misaligned trigger points. The template was then compared in a similar manner with every depolarization of the accelerated heart rate passage.

Correlation waveform analysis: The correlation co efficient $^{12-17}$ is a metric between \pm 1 which represents the morphologic similarity between 2 waveforms. It is a statistically based measure that is independent of amplitude and baseline variations and measures only relative shape differences between the template and the waveform being examined. This technique was used to compare the template depolarization with each depolarization from the control passage of sinus rhythm based on a previously published formula $a^{16}$ and correlation coefficients were averaged to yield a mean \pm standard deviation (CWA:SR). The average \pm standard deviation of correlation coefficients for each passage during subsequent intervention (CWA:INT) was also computed. Because correlation values of sinus rhythm were consistently high and approached 1 , we defined the percent change of correlation coefficient from the control sinus rhythm passage to the passage during intervention $(\Delta: C W A)$ according to the following formula:

$$
\Delta: \mathrm{CWA}=\left(\frac{\mathrm{CWA}: \mathrm{INT}-\mathrm{CWA}: \mathrm{SR}}{\mathrm{CWA}: \mathrm{SR}}\right) \times 100 \% .
$$

Area of difference analysis: Area of difference ${ }^{10,11}$ directly measures the absolute amplitude difference be- 


\begin{tabular}{|c|c|c|c|c|c|c|c|c|c|}
\hline Pt. No. & CWA:SR & CWA: 600 & $\begin{array}{l}\text { AOD:SR } \\
(\%)\end{array}$ & $\begin{array}{l}\text { AOD:600 } \\
(\%)\end{array}$ & $\begin{array}{l}\text { AMP:SR } \\
(\%)\end{array}$ & $\begin{array}{l}\text { AMP:600 } \\
(\%)\end{array}$ & $\begin{array}{l}\Delta: C W A \\
(\%)\end{array}$ & $\begin{array}{l}\triangle: A O D \\
(\%)\end{array}$ & $\begin{array}{l}\Delta: A M P \\
(\%)\end{array}$ \\
\hline 1 & $0.996 \pm 0.003$ & $0.995 \pm 0.003$ & $7 \pm 3$ & $34 \pm 1$ & $1 \pm 2$ & $8 \pm 11$ & -0.1 & +27 & +7 \\
\hline 6 & $0.994 \pm 0.001$ & $0.993 \pm 0.001$ & $16 \pm 5$ & $5 \pm 1$ & $-9 \pm 6$ & $5 \pm 11$ & -0.1 & -11 & +14 \\
\hline 8 & $0.998 \pm 0.001$ & $0.994 \pm 0.003$ & $6 \pm 2$ & $11 \pm 3$ & $1 \pm 2$ & $-6 \pm 19$ & -0.1 & +5 & -7 \\
\hline 10 & $0.997 \pm 0.001$ & $0.996 \pm 0.002$ & $8 \pm 3$ & $18 \pm 8$ & $1 \pm 4$ & $-12 \pm 2$ & -0.1 & +10 & -13 \\
\hline 34 & $0.988 \pm 0.00 /$ & $0.989 \pm 0.013$ & $12 \pm 3$ & $15 \pm 4$ & $1 \pm 9$ & $5 \pm 6$ & +0.1 & +3 & +4 \\
\hline 35 & $0.994 \pm 0.001$ & $0.988 \pm 0.004$ & $13 \pm 2$ & $17 \pm 5$ & $2 \pm 14$ & $-6 \pm 13$ & -0.6 & +4 & -8 \\
\hline
\end{tabular}

\begin{tabular}{|c|c|c|c|c|c|c|c|c|c|}
\hline Pt. No. & CWA:SR & CWA: 400 & $\begin{array}{l}\text { AOD:SR } \\
(\%)\end{array}$ & $\begin{array}{l}\text { AOD:400 } \\
(\%)\end{array}$ & $\begin{array}{l}\text { AMP:SR } \\
(\%)\end{array}$ & $\begin{array}{l}\text { AMP:400 } \\
(\%)\end{array}$ & $\begin{array}{l}\Delta: C W A \\
(\%)\end{array}$ & $\begin{array}{l}\triangle: A O D \\
(\%)\end{array}$ & $\begin{array}{l}\Delta: A M P \\
(\%)\end{array}$ \\
\hline 1 & $0.996 \pm 0.003$ & $0.979 \pm 0.004$ & $7 \pm 3$ & $53 \pm 2$ & $1 \pm 2$ & $8 \pm 2$ & -1.7 & +46 & +7 \\
\hline 6 & $0.994 \pm 0.001$ & $0.995 \pm 0.001$ & $16 \pm 5$ & $30 \pm 4$ & $-9 \pm 6$ & $41 \pm 10$ & +0.1 & +14 & +50 \\
\hline 8 & $0.998 \pm 0.001$ & $0.987 \pm 0.005$ & $6 \pm 2$ & $20 \pm 8$ & $1 \pm 2$ & $7 \pm 5$ & -1.1 & +14 & +6 \\
\hline 10 & $0.997 \pm 0.001$ & $0.988 \pm 0.002$ & $8 \pm 3$ & $78 \pm 13$ & $1 \pm 4$ & $19 \pm 16$ & -0.9 & +70 & +18 \\
\hline 34 & $0.988 \pm 0.007$ & $0.952 \pm 0.007$ & $12 \pm 3$ & $73 \pm 14$ & $1 \pm 9$ & $50 \pm 15$ & -3.6 & +61 & +49 \\
\hline 35 & $0.994 \pm 0.001$ & $0.981 \pm 0.006$ & $13 \pm 2$ & $28 \pm 9$ & $2 \pm 14$ & $29 \pm 18$ & -1.3 & +15 & +27 \\
\hline
\end{tabular}

tween associated sample points of the template and the waveform under analysis and is dependent on fluctuations in amplitude and baseline. To eliminate the effects of direct-current offset, a variation on this formulation that normalizes the absolute area of difference by the total area of the template has been derived. ${ }^{16}$ With use of this format, the area of difference was computed between the template depolarization and each depolarization of both the control passage of sinus rhythm and that during subsequent intervention, and these values were averaged to yield a mean \pm standard deviation for each passage (AOD:SR and AOD:INT). The percent change of the area of difference from the control passage of sinus rhythm to the passage during intervention $(\Delta: A O D)$ was calculated as follows:

\section{$\Delta: A O D=A O D: I N T-A O D: S R$}

Amplitude analysis: The difference in peak-to-peak electrogram amplitude due to intervention was also analyzed for each patient. The absolute peak-to-peak amplitude of the template depolarization $\left(\mathrm{PP}_{t m p}\right)$ and each depolarization of the baseline sinus rhythm passage $\left(\mathrm{PP}_{d e p}\right)$ was determined, and a normalized value representing the difference of amplitude between these depolarizations (AMP dep) was calculated as follows:

$$
\mathrm{AMP}_{\text {dep }}=\frac{\mathrm{PP}_{d e p}-\mathrm{PP}_{t m p}}{\mathrm{PP}_{t m p}} \times 100 \% .
$$

The normalized difference of amplitude values for all depolarizations of the baseline sinus rhythm passage were averaged to yield a mean \pm standard deviation for the passage (AMP:SR). The average \pm standard deviation of the difference of amplitude during subsequent intervention (AMP:INT) was computed similarly. Finally, the percent change of normalized difference of amplitude from the control passage of sinus rhythm to the passage during intervention ( $\triangle$ :AMP) was calculated as follows:

\section{$\Delta: \mathrm{AMP}=\mathrm{AMP}: \mathrm{INT}-\mathrm{AMP}: \mathrm{SR}$}

Scatter diagrams: Scatter diagrams of (1) the change of amplitude versus the change of correlation coefficient, and (2) the change of amplitude versus the change of area of difference were plotted for each intervention. When a linear probabilistic model was deemed appropriate (i.e., when the points tended to cluster about a straight line and when $\geq 10$ data points were available), linear regression analysis ${ }^{23}$ was used to obtain an equation of the estimated regression line. In each case, the change in amplitude was chosen to be the independent variable, and a best fit line to the data and the corresponding sample correlation coefficient, $r$, were determined.

\section{RESULTS}

Data from correlation waveform, area of difference and amplitude analyses during atrial overdrive pacing, infusions of epinephrine, and infusions of isoproterenol are summarized in Tables I to IV and are illustrated for 3 paticnts in Figures 1 to 3 . The width of the depolarization analysis window for the 35 patients of this study ranged from 29 to $100 \mathrm{~ms}$ (mean $51.2 \pm 14.8$ ). 
Cycle length: The sinus rhythm cycle length for group A patients was $765 \pm 99 \mathrm{~ms}$. Atrial overdrive pacing at $600 \mathrm{~ms}$ intervals decreased the cycle length by $161 \mathrm{~ms}(\mathrm{p}<0.02)$ and pacing at $400 \mathrm{~ms}$ intervals decreased the cycle length by $363 \mathrm{~ms}$ ( $\mathrm{p}<0.0005$ ). Epinephrine infusion decreased the mean sinus rhythm cycle length of $773 \pm 138 \mathrm{~ms}$ for group B patients by $88 \mathrm{~ms}(\mathrm{p}<0.005)$, and isoproterenol infusion decreased

\begin{tabular}{|c|c|c|c|c|c|c|c|c|c|}
\hline Pt. vo. & CWA:SR & CWA:EPI & $\begin{array}{l}\text { AOD:SR } \\
(\%)\end{array}$ & $\begin{array}{l}\text { AOD:EPI } \\
(\%)\end{array}$ & $\begin{array}{l}\text { AMP:SR } \\
(\%)\end{array}$ & $\begin{array}{l}\text { AMP:EPI } \\
(\%)\end{array}$ & $\begin{array}{l}\Delta: C W A \\
(\%)\end{array}$ & $\begin{array}{l}\Delta: A O D \\
(\%)\end{array}$ & $\begin{array}{l}\Delta: A M P \\
(\%)\end{array}$ \\
\hline 1 & $0.996 \pm 0.003$ & $0.996 \pm 0.003$ & $7 \pm 3$ & $14 \pm 2$ & $1 \pm 2$ & $8 \pm 8$ & 0.0 & +7 & +7 \\
\hline 2 & $0.999 \pm 0.001$ & $0.998 \pm 0.001$ & $11 \pm 3$ & $11 \pm 3$ & $1=13$ & $-3 \pm 10$ & -0.1 & 0 & -4 \\
\hline 3 & $0.992 \pm 0.005$ & $0.983 \pm 0.006$ & $13 \pm 3$ & $16 \pm 2$ & $-1 \pm 7$ & $-8 \pm 9$ & -0.9 & +3 & -7 \\
\hline 4 & $0.994 \pm 0.005$ & $0.983 \pm 0.007$ & $12 \pm 5$ & $15 \pm 2$ & $2 \pm 9$ & $1 \pm 3$ & -1.1 & +3 & -1 \\
\hline 5 & $0.996 \pm 0.001$ & $0.980 \pm 0.003$ & $9 \pm 2$ & $17 \pm 2$ & $-1 \pm 3$ & $1 \pm 8$ & -1.6 & +8 & +2 \\
\hline 6 & $0.994 \pm 0.001$ & $0.990 \pm 0.002$ & $16 \pm 5$ & $13 \pm 2$ & $-9 \pm 6$ & $-5 \pm 5$ & -0.4 & -3 & +4 \\
\hline 7 & $0.993 \pm 0.002$ & $0.989 \pm 0.001$ & $11 \pm 2$ & $16 \pm 2$ & $6 \pm 6$ & $6 \pm 36$ & -0.4 & +5 & 0 \\
\hline 8 & $0.998 \pm 0.002$ & $0.993 \pm 0.004$ & $6 \pm 2$ & $12 \pm 3$ & $1 \pm 2$ & $5 \pm 4$ & -0.5 & +6 & +4 \\
\hline 9 & $0.982 \pm 0.012$ & $0.982 \pm 0.009$ & $44 \pm 25$ & $21 \pm 7$ & $18 \pm 29$ & $2 \pm 23$ & 0.0 & -23 & -16 \\
\hline 10 & $0.997 \pm 0.001$ & $0.997 \pm 0.001$ & $8 \pm 3$ & $15 \pm 6$ & $1 \pm 4$ & $7 \pm 6$ & 0.0 & +7 & +6 \\
\hline 11 & $0.996 \pm 0.002$ & $0.975 \pm 0.009$ & $18 \pm 6$ & $26 \pm 5$ & $5 \pm 14$ & $-8 \pm 14$ & -2.1 & +8 & -13 \\
\hline 12 & $0.994 \pm 0.003$ & $0.982 \pm 0.008$ & $12 \pm 2$ & $29 \pm 9$ & $3 \pm 3$ & $12 \pm 13$ & -1.2 & +17 & +9 \\
\hline $13^{*}$ & $0.982 \pm 0.011$ & $0.890 \pm 0.018$ & $17 \pm 6$ & $39 \pm 5$ & $-8 \pm 4$ & $-11 \pm 19$ & -9.4 & +23 & -3 \\
\hline
\end{tabular}

TABLE IV Results of Morphologic Analysis of Isoproterenol Infusion

\begin{tabular}{|c|c|c|c|c|c|c|c|c|c|}
\hline Pt. No. & CWA:SR & CWA:ISO & $\begin{array}{l}\text { AOD:SR } \\
(\%)\end{array}$ & $\begin{array}{l}\text { AOD:ISO } \\
(\%)\end{array}$ & $\begin{array}{l}\text { AMP:SR } \\
(\%)\end{array}$ & $\begin{array}{l}\text { AMP:ISO } \\
(\%)\end{array}$ & $\begin{array}{l}\Delta: C W A \\
(\%)\end{array}$ & $\begin{array}{l}\triangle: A O D \\
(\%)\end{array}$ & $\begin{array}{l}\Delta: A M P \\
(\%)\end{array}$ \\
\hline 14 & $0.995 \pm 0.003$ & $0.967 \pm 0.030$ & $19 \pm 8$ & $34 \pm 11$ & $-33 \pm 10$ & $-24 \pm 15$ & -2.8 & +15 & +9 \\
\hline 15 & $0.997 \pm 0.002$ & $0.994 \pm 0.005$ & $7 \pm 2$ & $12 \pm 2$ & $1 \pm 4$ & $-2 \pm 6$ & -0.3 & +5 & -3 \\
\hline 16 & $0.996 \pm 0.022$ & $0.973 \pm 0.015$ & $10 \pm 4$ & $54 \pm 31$ & $-1 \pm 5$ & $8 \pm 23$ & -2.3 & +44 & +9 \\
\hline 17 & $0.996 \pm 0.002$ & $0.997 \pm 0.001$ & $19 \pm 5$ & $23 \pm 5$ & $13 \pm 15$ & $25 \pm 16$ & +0.1 & +4 & +12 \\
\hline 18 & $0.996 \pm 0.002$ & $0.991 \pm 0.002$ & $15 \pm 5$ & $53 \pm 13$ & $2 \pm 10$ & $23 \pm 13$ & -0.5 & +38 & +21 \\
\hline 19 & $0.996 \pm 0.003$ & $0.995 \pm 0.003$ & $10 \pm 4$ & $14 \pm 3$ & $-2 \pm 3$ & $8 \pm 4$ & -0.1 & +4 & +10 \\
\hline 20 & $0.995 \pm 0.003$ & $0.975 \pm 0.002$ & $11 \pm 2$ & $43 \pm 1$ & $-4 \pm 2$ & $-4 \pm 6$ & -2.0 & +32 & 0 \\
\hline 21 & $0.996 \pm 0.002$ & $0.997 \pm 0.001$ & $11 \pm 5$ & $11 \pm 5$ & $-9 \pm 7$ & $3 \pm 11$ & +0.1 & 0 & +12 \\
\hline 22 & $0.967 \pm 0.012$ & $0.953 \pm 0.007$ & $39 \pm 17$ & $62 \pm 17$ & $29 \pm 26$ & $48 \pm 14$ & -1.5 & +23 & +19 \\
\hline 23 & $0.998 \pm 0.002$ & $0.981=0.016$ & $6 \pm 2$ & $26 \pm 8$ & $0 \pm 3$ & $17 \pm 10$ & -1.7 & +20 & +17 \\
\hline 24 & $0.997 \pm 0.002$ & $0.997=0.001$ & $5 \pm 2$ & $22 \pm 4$ & $0 \pm 4$ & $10 \pm 6$ & 0.0 & +17 & +10 \\
\hline 25 & $0.997 \pm 0.002$ & $0.996=0.002$ & $15 \pm 5$ & $12 \pm 5$ & $-1 \pm 6$ & $-6 \pm 6$ & -0.1 & -3 & -5 \\
\hline 26 & $0.996 \pm 0.001$ & $0.996=0.002$ & $15 \pm 7$ & $48 \pm 13$ & $-3 \pm 14$ & $53 \pm 15$ & 0.0 & +33 & +56 \\
\hline 27 & $0.990 \pm 0.003$ & $0.962=0.009$ & $24 \pm 8$ & $57 \pm 2$ & $-10 \pm 11$ & $-1 \pm 7$ & -2.8 & +33 & +9 \\
\hline 28 & $0.996 \pm 0.002$ & $0.993 \pm 0.002$ & $13 \pm 5$ & $14 \pm 4$ & $0 \pm 8$ & $4 \pm 3$ & -0.3 & +1 & +4 \\
\hline 29 & $0.996 \pm 0.004$ & $0.996=0.002$ & $10 \pm 5$ & $12 \pm 2$ & $-2 \pm 12$ & $26 \pm 11$ & 0.0 & +2 & +28 \\
\hline 30 & $0.990 \pm 0.005$ & $0.961 \pm 0.039$ & $18 \pm 3$ & $50 \pm 20$ & $-10 \pm 23$ & $-6 \pm 8$ & -3.0 & +32 & +4 \\
\hline 31 & $0.995 \pm 0.002$ & $0.994=0.002$ & $10 \pm 5$ & $15 \pm 5$ & $-1 \pm 5$ & $4 \pm 4$ & -0.1 & +5 & +5 \\
\hline $32^{*}$ & $0.968 \pm 0.012$ & $0.759 \pm 0.003$ & $24 \pm 5$ & $63 \pm 9$ & $7 \pm 5$ & $130 \pm 8$ & -21.6 & +39 & +123 \\
\hline $33^{*}$ & $0.992 \pm 0.004$ & $0.786 \pm 0.009$ & $19 \pm 9$ & $261 \pm 8$ & $-1 \pm 9$ & $12 \pm 7$ & -20.8 & +242 & +13 \\
\hline
\end{tabular}

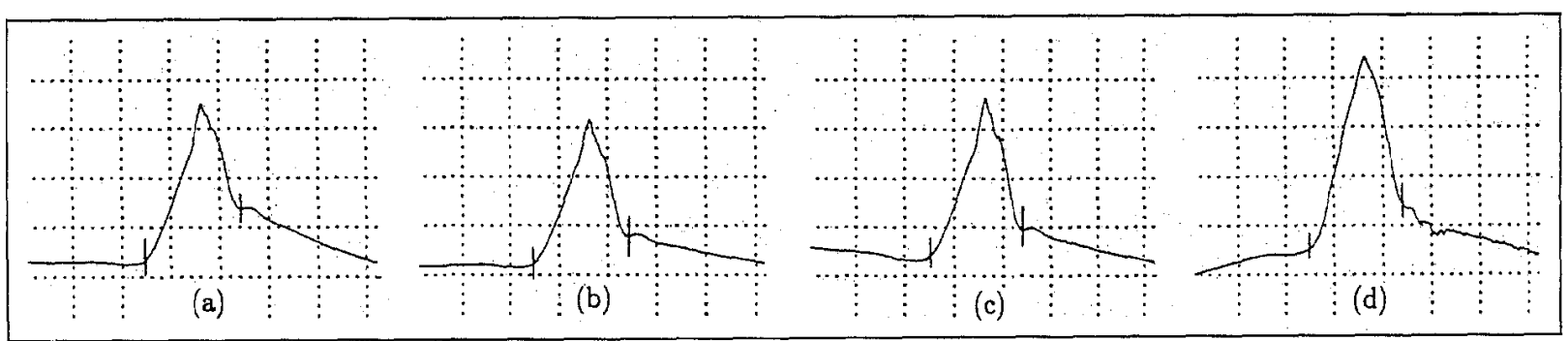

FIGURE 1. Electrograms from patient 6 during atrial overdrive pacing at rates of 600 and $400 \mathrm{~ms}$. A signal-averaged intravenIricular depolarization is shown from a passage during (a) sinus ihythm for template construction, (b) a subsequent control passage of sinus rhythm, (c) pacing at $600 \mathrm{~ms}$, and (d) pacing at $400 \mathrm{~ms}$. The figures are plotted at a paper speed of $200 \mathrm{~mm} / \mathrm{s}$ with a gain of $100 \mathrm{mV} / \mathrm{mm}$. The $51 \mathrm{~ms}$ analysis window of electrogram depolarization is marked by vertical bars on the original $180 \mathrm{~ms}$ window. Although the change in correlation coefficient was small during pacing at both 600 and $400 \mathrm{~ms}(-0.1$ and $+0.1 \%)$, larger changes in area of difference $(-11$ and $+14 \%)$ and amplitude $(+14$ and $+50 \%)$ occurred. 
the sinus rhythm cycle length of $797 \pm 151 \mathrm{~ms}$ for group $\mathrm{C}$ patients by $231 \mathrm{~ms}(\mathrm{p}<0.0001)$. With the exception of 1 patient (no. 13), no consistent relationship could be found between the change in cycle length due to any intervention and the change of correlation coefficient, area of difference, or amplitude of the electrogram.

Correlation waveform analysis: For 6 of 6 group A patients $(100 \%)$, the change in correlation coefficient during pacing at $600 \mathrm{~ms}$ intervals ranged from -0.6 to $+0.1 \%$ and averaged $-0.2 \%$. During pacing at a cycle length of $400 \mathrm{~ms}$, the change in correlation coefficient ranged from -3.6 to $+0.1 \%$ and averaged $-1.4 \%$.

The change in correlation coefficient for 12 of 13 patients (92\%) during epinephrine infusion (group B) ranged from -2.1 to $0 \%$ and averaged $-0.7 \%$. A large, unexplained change of correlation coefficient $(9.4 \%)$ was seen in 1 patient (no. 13).

The change in correlation coefficient for 18 of 20 patients (90\%) during isoproterenol infusion (group C) ranged from -2.8 to $+0.1 \%$ and averaged $-1.0 \%$. Two group C patients (nos. 32 and 33) had a paradoxical change of correlation coefficient of -20.8 and $-21.6 \%$.

Area of difference analysis: For patients in group A, the change of area of difference during atrial overdrive pacing at a cycle length of $600 \mathrm{~ms}$ ranged from -11 to $+27 \%$ and averaged $+6 \%$. Pacing at a cycle length of $400 \mathrm{~ms}$ produced a change in area of difference that ranged from +14 to $+70 \%$ and averaged $+37 \%$.

For the 12 of 13 group B patients with stable correlation coefficients during epinephrine infusion, the change in area of difference ranged from -23 to $+17 \%$ and averaged $+3 \%$.

For the 18 of 20 group $C$ patients with stable correlation coefficients during isoproterenol infusion, the change in area of difference ranged from -3 to $+44 \%$ and averaged $+17 \%$.

Amplitude analysis: The change in amplitude for group A patients during atrial overdrive pacing at a cycle length of $600 \mathrm{~ms}$ ranged from -13 to $+14 \%$ and averaged $-1 \%$. The change in amplitude during pacing at a cycle length of $400 \mathrm{~ms}$ ranged from +6 to $+50 \%$ and averaged $+26 \%$.

For the 12 patients from group B with stable correlation coefficients during epinephrine infusion, the change in amplitude ranged from -16 to $+9 \%$ and averaged $-1 \%$.

For the 18 group $\mathrm{C}$ patients with stable correlation coefficients during isoproterenol infusion, the change in amplitude ranged from -5 to $+56 \%$ and averaged $+12 \%$.

Scatter diagrams: Figures 4 and 5 illustrate the scatter plots of change of amplitude versus change of correlation coefficient and change of amplitude versus

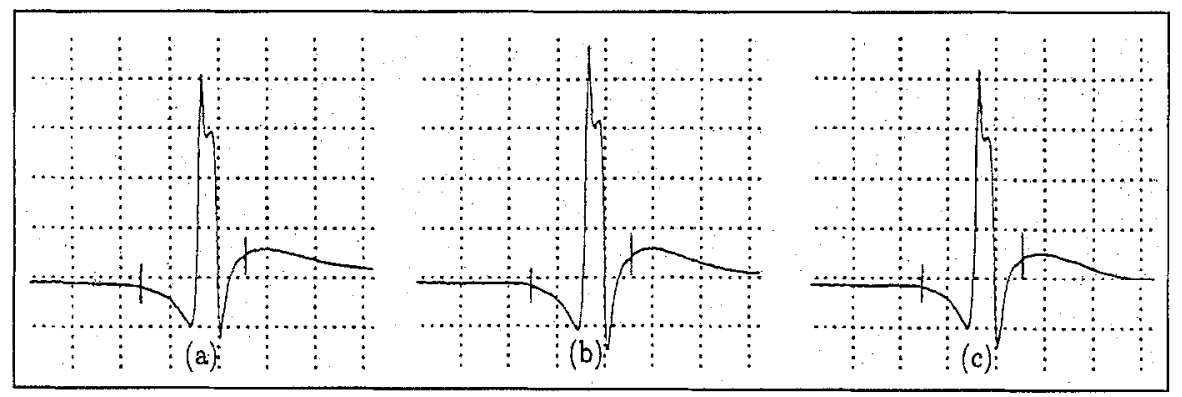

FIGURE 2. Electrograms from patient 9 during infusion of epinephrine. A signal-averaged intraventricular depolarization is shown from (a) passage of sinus thythm for template construction, (b) a subsequent control passage of sinus rhythm, and (c) passage during epinephrine infusion. The figures are plotted at a paper speed of $200 \mathrm{~mm} / \mathrm{s}$ with a gain of $50 \mathrm{mV} / \mathrm{mm}$. The 53 ms analysis window of electrogram depolarization is marked on the original $180 \mathrm{~ms}$ window. This patient had no change in correlation coefficient. However, changes in area of difference $(-23 \%)$ and amplitude $(-16 \%)$ during epinephrine infusion occurred.

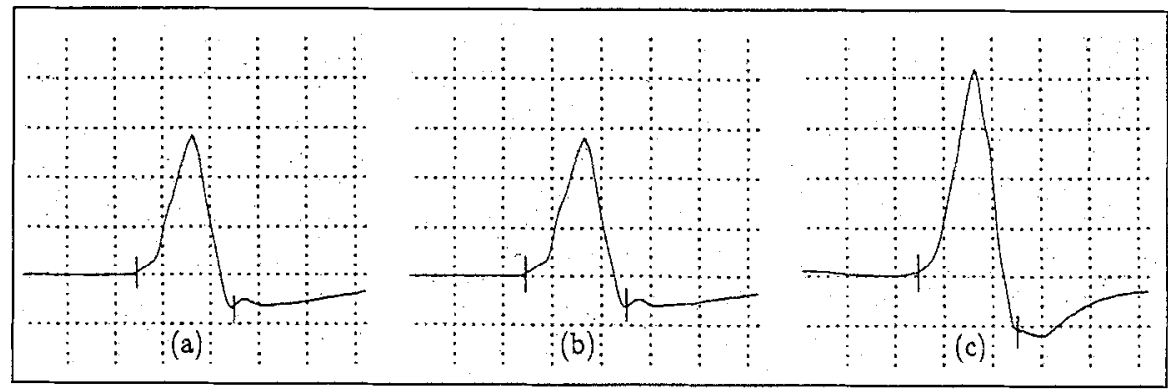

FIGURE 3. Electrograms from patient 26 during isoproterenol infusion. A signal-averaged intraventricular depolarization is shown from (a) passage of sinus ihythm for template construction, (b) a subsequent control passage of sinus ihythm, and (c) the passage during isoproterenol infusion. The figures are plotted at a paper speed of $200 \mathrm{~mm} / \mathrm{s}$ with a gain of $75 \mathrm{mV} / \mathrm{mm}$. The 52 ms analysis window of electrogram depolarization is marked on the original $180 \mathrm{~ms}$ window. Although no change of correlation coefficient occurred, a large change in area of difference $(+33)$ and amplitude $(+56 \%)$ during isoproterenol infusion occurred. 
change of area of difference for the 36 patients with stable correlation coefficients during each intervention. Patients with paradoxical changes in correlation coefficient (nos. 13, 32 and 33) were not included in the analysis. For both figures, the data points for pacing at intervals of 600 and $400 \mathrm{~ms}$ are not clustered and are too few for linear regression to be appropriate. However, a tighter clustering of data is evident during infusions of epinephrine and isoproterenol, and results of linear regression analysis are included in these diagrams. Whereas changes in amplitude and correlation coefficient were only weakly correlated during both infusion of epinephrine $(\mathrm{r}=0.187)$ and isoproterenol $(r=0.217)$, the change in amplitude and the change in area of difference were moderately correlated during infusion of epinephrine $(r=0.649)$ and weakly correlated during infusion of isoproterenol $(r=0.292)$.

\section{DISCUSSION}

Correlation waveform analysis remains stablc during interventional increases in heart rate, whereas the area of difference is less stable and exhibits moderate fluctuations associated with amplitude changes (Figures 1 to 3 ). Overall waveform morphology remains relatively constant (despite some amplitude variation) during increases in heart rate with or without concurrent changes in sympathetic tone. Therefore, it may be anticipated that a sophisticated scheme of pattern recognition, using a template-based system of arrhythmia identification and regular updating of the sinus rhythm

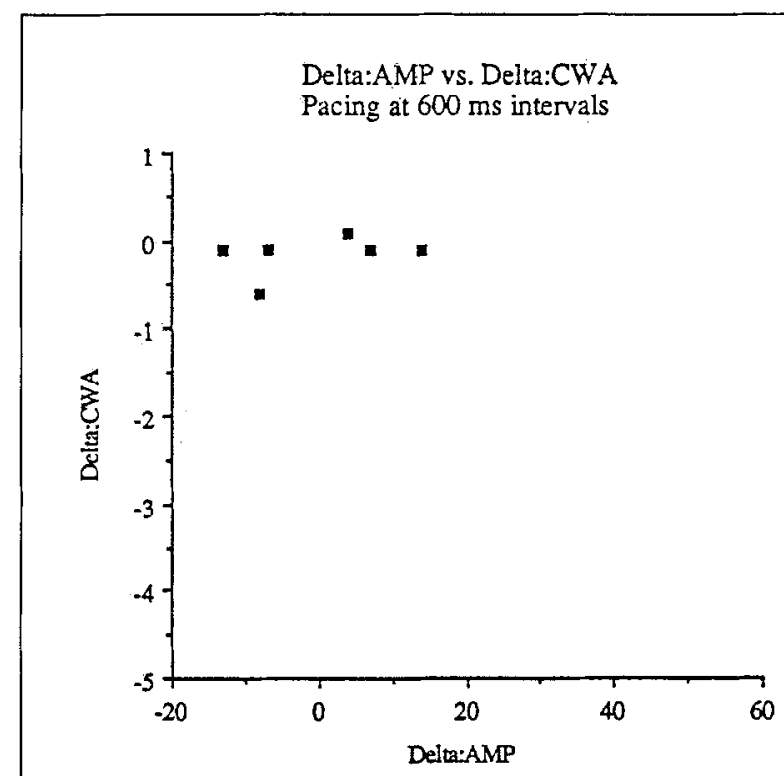

(a)

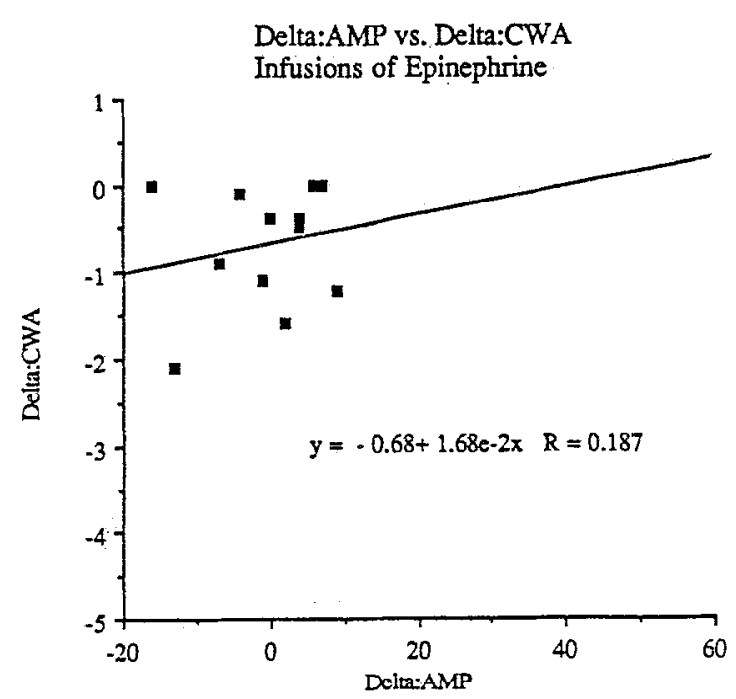

(c)
Delta:AMP.vs. Delta:CWA

Pacing at $400 \mathrm{~ms}$ intervals

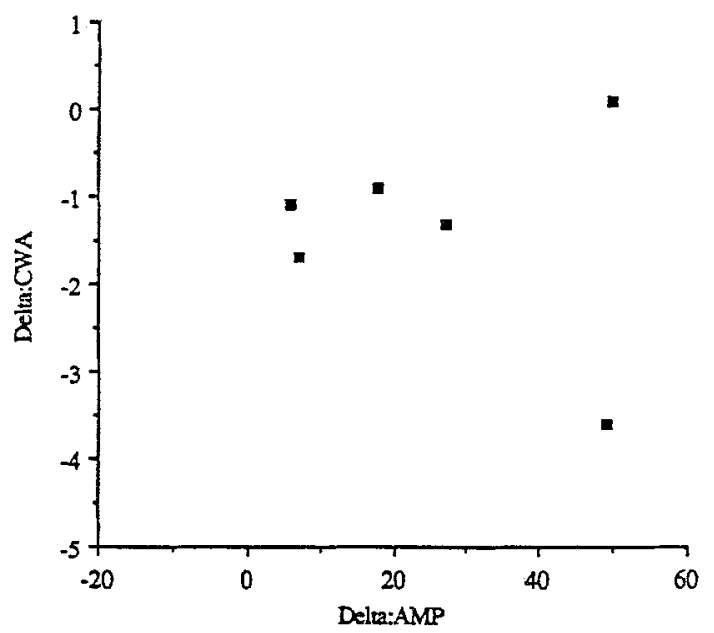

(b)

Delta:AMP vs. Delta:CWA

Infusions of Isoproterenol

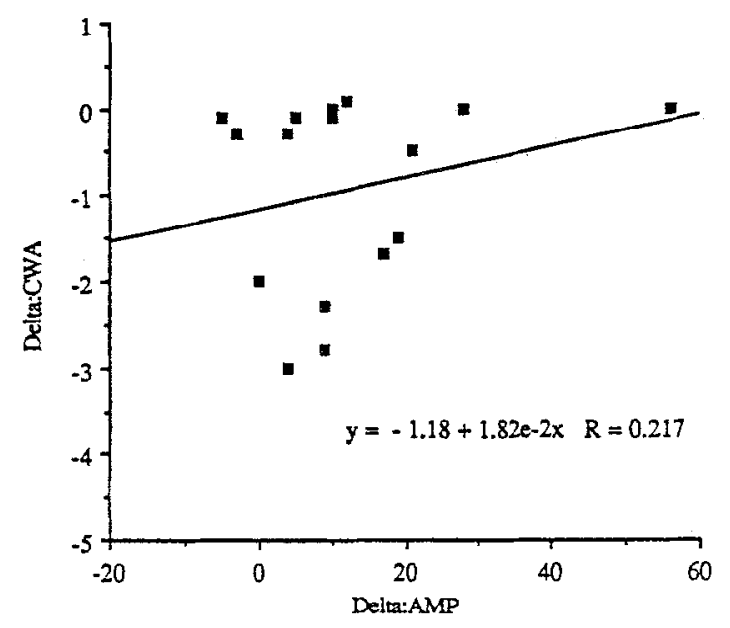

(d) 
template, should not be confounded by increases in heart rate during sinus rhythm.

Results of 3 patients undergoing pharmacologic intervention, 1 during epinephrine (no 13) and 2 during isoprotercnol (nos, 32 and 33) administration, were widely divergent from most patients evaluated in this study. The morphologic changes noted in these patients, as assessed by the 12-lead electrocardiogram, were not due to paroxysmal development of an intraventricular conduction delay (such as bundle branch block) during drug infusions. Because passive intracardiac electrode leads were used, and because baseline sinus rhythm passages after excretion of exogenously administered drugs were not reconfirmed for stability of electrode location, catheter movement cannot be ex- cluded as a potential cause of the observed changes. For these reasons, we purposely excluded these 3 patients from our statistical analysis and conclusions because of the ambiguity they posed.

Correlation waveform analysis: $\mathrm{N}$ though this study indicated that correlation waveform analysis remains stable in the presence of accelerated heart rate, other investigators have shown contradictory results. Paul et $\mathrm{al}^{18}$ demonstrated large changes in electrogram morphology using correlation waveform analysis in a small number of patients during changes in body position. As in the current study, Paul also used a passive electrode catheter, and although data were obtained immediately after exercise, electrograms were not recorded after complete recovery to confirm whether a close correla-

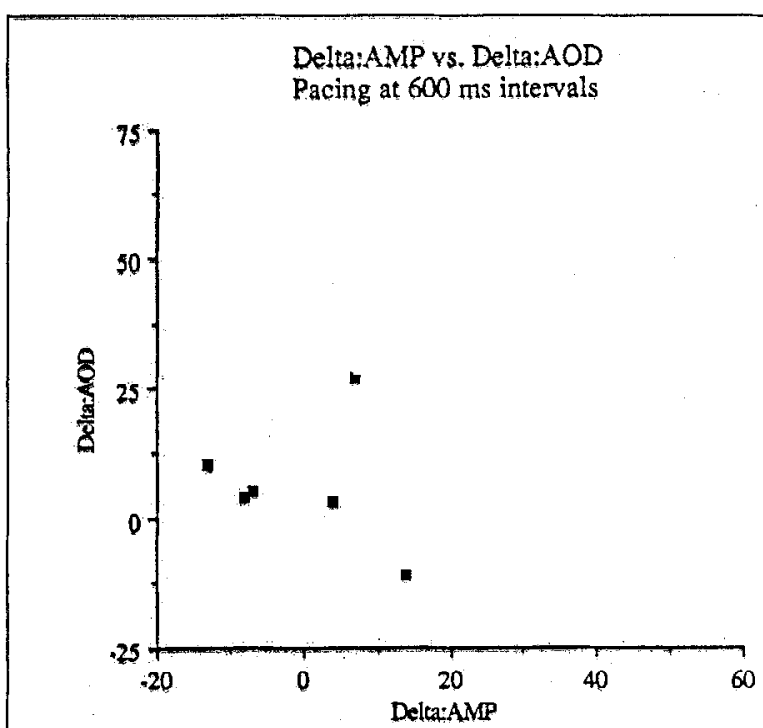

(a)

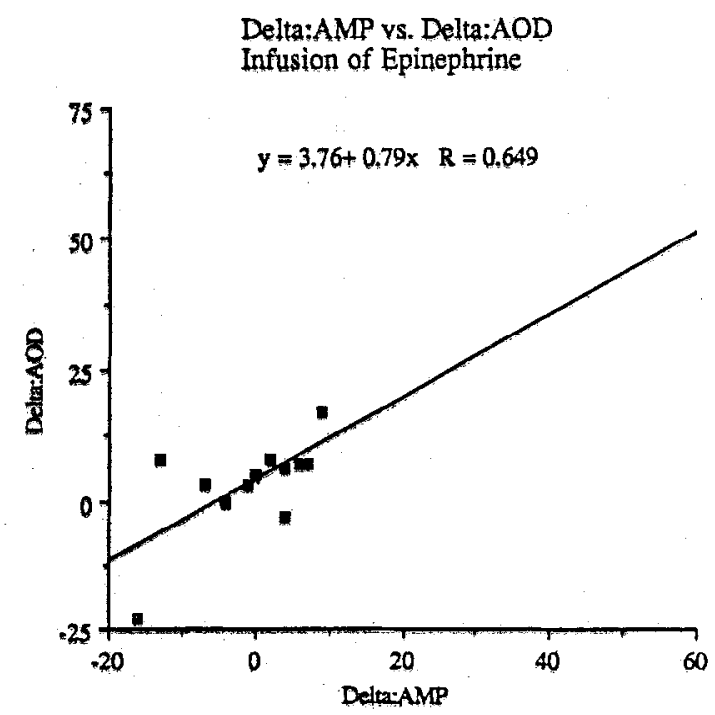

(c)

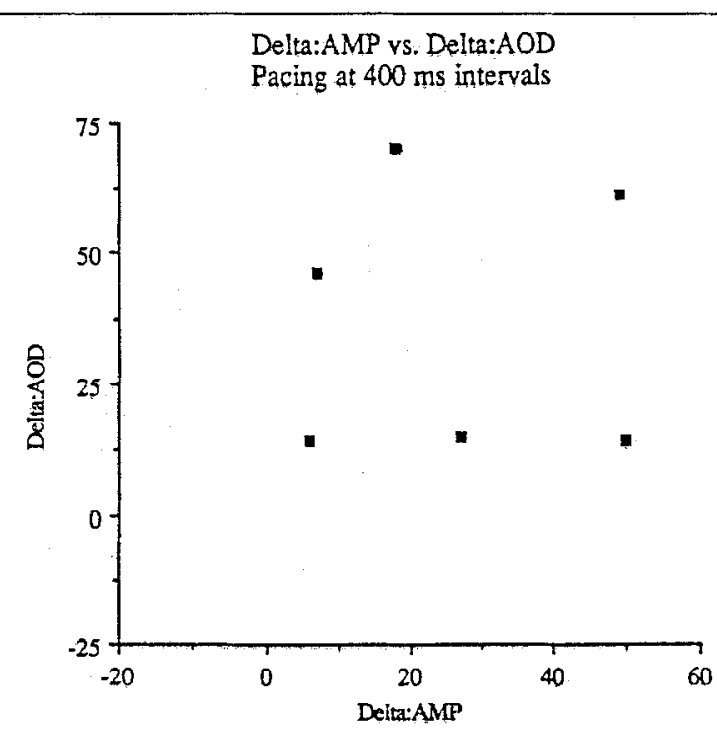

(b)

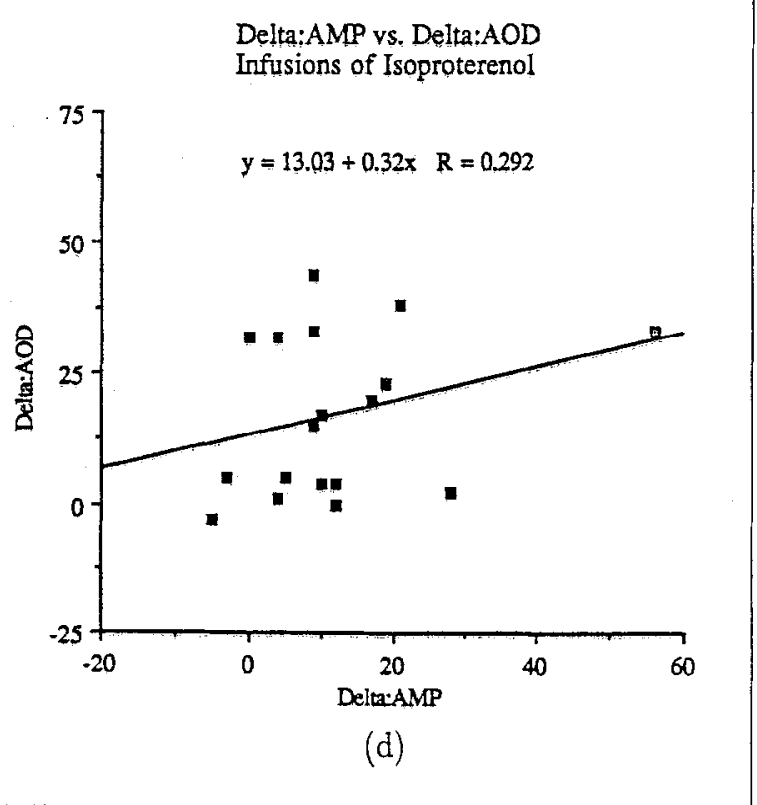

FIGURF 5. Seatter dingrams of the change in amplitude (DeltarAMP) versus the change in area of difference (DeltaHAOD) during (a) atrial overdrive pacing at a cycle length of $600 \mathrm{~ms}$, (b) pacing at a cycle length of $400 \mathrm{~ms}$, (c) epinephrine infusion, and (d) icoproterenol infusion. Panels (c) and (d) include linear regression analysis. 
tion with the original sinus rhythm template remained. Therefore, as with the 3 patients in the current study, catheter migration cannot be excluded as a cause for their observed results.

Area of difference analysis; In the present study moderate fluctuations in area of difference that occurred with interventional increases in heart rate were noted. They may not necessarily prove troublesome to template-matching schemes, because the range of area of difference values obtained during accelerated heart rate passages is similar to that previously reported for sinus rhythm at rest, ${ }^{10,15}$ The findings of this study therefore suggest that accelerated heart rate may not confound the ability of this technique of analysis to differentiate ventricular tachycardia from sinus rhythm.

Amplitude analysis: Although changes in amplitude due to increased heart rate have been demonstrated in previous studies, ${ }^{19,24,25}$ controversy exists concerning the value of electrogram amplitude in detecting diverse dysrhythmias, ${ }^{10,11,26-28}$ The present study measured peak-to-peak amplitude changes on raw, unfiltered data. The observed effects of atrial overdrive pacing at fast cycle lengths and of isoproterenol administration on electrogram amplitude in the present study are compatible with those of Rosenheck et al. ${ }^{19}$ However, they reported amplitude increases during atrial overdrive pacing at $400 \mathrm{~ms}$ intervals and during $\beta$ agonism caused by isoproterenol administration as seen on a high-pass filtered version of the signal. As a result, their study consisted of analysis of the derivative of the intracardiac signal, rather than the signal itself.

Studies to date concerning time-domain analysis of intracardiac electrograms have been hampered by experimental limitations such as passive electrode leads, lack of confirmation of electrode migration, and use of artificial intervention to simulate physiologic changes in heart rate. Despite these limitations, the importances of the present study are twofold: (1) Amplitude changes, as seen in the presence of accelerated heart rate, are not necessarily accompanied by significant changes in electrogram morphology as assessed by correlation waveform or area of difference analyses. (2) Electrogram morphologic analysis for the discrimination of ventricular tachycardia from sinus rhythm should remain robust in the face of physiologically accelerated heart rate.

Acknowledgment: We wish to thank Judy Jaffke, AS, and Kathleen Matney, RN, for their technical assistance in the cardiac electrophysiology laboratory.

\section{REFERENCES}

1. Olson WH, Bardy GH, Mehra, R, Keimel JG, Huberty KP, Almquist C, Biallas RM. Onset and stability for ventricular tachyarrhythmia detection in an implantable pacer-cardioverter-defibrillator. IEEE Comp Cardiol 1987:167-170. 2. Arzbaecher R, Bump T, Jenkins J, Glick K, Munkenbeck F, Brown J, Nandha- kumar N. Automatic tachycardia recognition. PACE 1984;7:54l-547. 3. Jenkins J, Bump T, Munkenbeck F, Brown J, Arzbaecher R. Tachycardia detection in implantable antitachycardia devices. PACE 1984;7:1273-1277. 4. Walsh CA, Singer LP, Mercando AD, Furman S. Differentiation of arrhythmias in the dog by measurement of activation sequence using an atrial and two ventricular electrodes. PACE 1988;11:1732-1738.

5. Davies DW, Wainwright RJ, Tooley MA, Lloyd D, Nathan AW, Spurrell RA, Camm AJ. Detection of pathological tachycardia by analysis of electrogram morphology. PACE 1986;9:200-208.

6. Davies DW, Tooley MA, Cochrane T, Nathan AW, Wainwright RJ, Camm AJ. Real time tachycardia diagnosis using morphological analysis of electrograms (abstr). PACE 1987;10(suppl II):II-998.

7. Lindsay BD, Ambos HD, Schechtman KB, Cain ME. Improved differentiation of patients with and without ventricular tachycardia by frequency analysis of multiple electrocardiographic leads. Am J Cardiol 1988;62:556-561.

8. Pannizzo F, Furman S. Frequency spectra of ventricular tachycardia and sinus rhythm in human intracardiac electrograms - application to tachycardia detection for cardiac pacemakers. IEEE Trans Biomed Eng 1988;35:421-425.

9. Slocum J, Sahakian A, Swiryn S. Computer discrimination of atrial fibrillation and regular atrial rhythms from intra-atrial electrograms. $P A C E$ 1988;11: $610-621$.

10. Langberg JL, Gibb WJ, Auslander DM, Griffin JC. Identification of ventricular tachycardia with use of the morphology of the endocardial electrogram. Circulation 1988;77:1363-1369.

11. Tomaselli GF, Nielsen AP, Finke WL, Singupta L, Clark JC, Griffin JC. Morphologic differences of the endocardial electrogram in beats of sinus and ventricular origin. PACE 1988;11:254-262.

12. Lin D, Jenkins JM, Wiesmeyer MD, Jadvar H, DiCarlo LA. Analysis of time and frequency domain patterns of endocardial electrograms to distinguish ventricular tachycardia from sinus rhythm. IEEE Comp Cardiol 1987:171-174.

13. Lin D, DiCarlo LA, Jenkins JM. Identification of ventricular tachycardia using intracavitary ventricular electrograms: analysis of time and frequency domain patterns. PACE 1988;11:1592-1606.

14. Throne RD, Jenkins JM, Winston SA, Finelli CJ, DiCarlo LA. Discrimination of retrograde from anterograde atrial activation using intracardiac electrogram waveform analysis. PACE 1989;12:1622-1630.

15. Throne RD, Jenkins JM, Wiuston SA, DiCarlo LA. Use of lacliycardia templates for recognition of recurrent monomorphic ventricular tachycardia. IEEE Comp Cardiol 1989:171-174.

16. Thrune RD, DiCarlo LA, Jenkins JM, Winston SA. Paroxysmal bundle branch block of supraventricular origin: a possible source of misdiagnosis in detecting ventricular tachycardia using time domain analysis of intraventricular electrograns. PACE 1990;13:453-468.

17. Throne RD, Jenkins JM, DiCarlo LA. Intraventricular electrogram analysis for ventricular tachycardia detection: statistical validation. PACE 1990;13: 1596-1601.

18. Paul VE, Bashir Y, Murphy T, Malik M, Samaurez R, Camm A.J. Variability of the intracardiac electrogram: effect on specificity of tachycardia detection. PACE 1990;13:1925-1929.

19. Rosenheck S, Schmaltz S, Kadish AH, Morady F. Effect of rate augmentation and isoproterenol on the amplitude of atrial and ventricular electrograms. $A m$ $J$ Cardiol 1990;66:101-102.

20. Tomaselli GF, Gibb WJ, Langberg JJ, Chin MC, Griffin JC. In vivo testing of a morphology based approach to cardiac rhythm identification using the endocardial electrogram (abstr). Circulation 1987;76(suppl IV):IV-280.

21. Morady F, Nelson SD, Kuo WH, Pratley R, Schmaltz S, deBuitleir M, Halter JB. Electrophysiologic effects of epinephrine in humans. J Am Coll Cardiol 1988;11:1235-1244.

22. Khan MG. Manual of Cardiac Drug Therapy. Philadelphia, PA: WB Saunders, 1988:235-237.

23. Devore JL. Probability \& Statistics for Engineering and the Sciences. Monterey, CA: Brooks/Cole, 1982:422-458.

24. Bricker JT, Ward KA, Zinner A, Gillette PC. Decrease in canine endocardial and epicardial electrogram voltages with exercise: Implications for pacemaker sensing. PACE 1988;11:460-464.

25. Ross BA, Zinner A, Ziegler V, Woodall $P$, Gillette PC. The effect of exercise on the atrial electrograms in humans (abstr). J Am Coll Cardiol 1987;9:32A. 26. Bella PD, Brugada $P$, Dugernier $T$, Lemery R, Wellens HJJ. Transventricular lead system for identification and termination of tachycardias (abstr). Circulation 1986;74(suppl II):183.

27. Leitch JW, Yee R, Klein GJ, Jones DL, Murdock CJ. Correlation between the ventricular electrogram amplitude in sinus rhythm and in ventricular fibrillation. PACE 1990;13:1105-1109.

28. Timmis GC, Westveer DC, Bakalyar DM, Pugsley TJ, Stewart JR, Gordon $\mathrm{S}$. Discrimination of anterograde from retrograde atrial electrograms for physiologic pacing. PACE 1988;11:130-140. 